Socio-Economic Review, DOI: https://doi-org/10.1093/ser/mww033. Please cite the published version.

\title{
Seeing Like a Market ${ }^{\star}$
}

\author{
Marion Fourcade \\ University of California, Berkeley \\ fourcade@berkeley.edu
}

\author{
Kieran Healy \\ Duke University \\ kjhealy@soc. duke.edu
}

\begin{abstract}
What do markets see when they look at people? Information dragnets increasingly yield huge quantities of individual-level data, which is analyzed to sort and slot people into categories of taste, riskiness, or worth. Developed to better understand and improve customer experience, these tools deepen the reach of the market and define new strategies of profit-making. We present a new theoretical framework for understanding them. We argue that (1) modern organizations follow an institutional data imperative to collect as much data as possible; (2) as a result of the analysis and use of this data individuals accrue ubercapital, a form of capital flowing from their positions as measured by various digital scoring and ranking methods; and, (3) the facticity of these scoring methods makes them organizational devices with powerful classifying effects. They offer firms new opportunities to structure and price offerings to consumers. For individuals, they create classification situations that identify shared life-chances in product and service markets.
\end{abstract}

*The authors are grateful to Jenna Burrell, Patrick Chanezon, Paul Duguid, Jean-Louis Fabiani, Christopher Hoofnagle, Karoline Krenn, Akos Rona-Tas, Nina Bandelj and two anonymous SER reviewers for helpful comments on this paper. We also thank Daniel Kluttz for excellent research assistance. Earlier versions of this article were presented at the annual meetings of the American Sociological Association, the "Money Talks" conference at Yale University, the "Phenomenology of Organizations" conference at Boston College, the "Classification Situations" conference at Humboldt University, and seminars at the Duke University, UC Berkeley Social Science Matrix, the UC Berkeley i-school, UC Irvine, and UC Santa Cruz. 
We discuss the implications of these processes and argue that they tend towards a new economy of moral judgment, where outcomes are experienced as morally deserved positions based on prior good actions and good tastes, as measured and classified by this new data infrastructure of data collection and analysis.

Across institutional domains, tracking and measurement is expanding and becoming ever more fine-grained (Limn, 2012; Gillespie et al., 2014; Pasquale, 2015). We see it in everyday consumption, in housing and credit markets, in health, employment, education (Cottom, 2016), social relations, including intimate ones (Levy, 2015), legal services, and even into political life (Ziewitz, 2016) and the private sphere (Neff and Nafus, 2016). Sociologists studying the state, technology and the market have sought to describe and understand these trends in different ways. This article proposes a framework to analytically unify their concerns, and to grasp the implications of contemporary technological developments for processes of inequality and stratification.

We discuss the emergence and consolidation of a new regime of moralized social classification, backed by algorithmic techniques and dependent on large volumes of quantitative data (O’Neil, 2016). Digital traces of individual behaviors (where classifying instruments define what 'behavior' is, and how it should be measured) are increasingly aggregated, stored and analyzed. As new techniques allow for the matching and merging of data from different sources, the results crystallize-for the individuals classified-into what looks like a supercharged form of capital. This 'übercapital', or 'eigencapital', as we call it, is any form of capital arising from one's digital records. Think, for instance, of measures of financial responsibility, social network influence, healthy bodily habits or productivity at work. Like Scott's (1999) administrative designs, digital economy's classificatory architecture allows market institutions to apprehend their clients, customers, or employees through new instruments of knowledge, efficiency and value extraction. Markets have learned to 'see' in a new way, and are teaching us to see ourselves in that way, too.

Although their designers often display a 'high modernist' belief in the ability of these technologies to bring everyone into their fold for the betterment of humanity, their social consequences are much more ambivalent. The new lenses generate classification situations (Fourcade and Healy, 2013): They are used as a basis for the production of consequential forms of social categorization and price-differentiated opportunities. On the basis of their digital records, individuals are sorted and scored, then slotted and matched for the purpose of maximizing profit. We outline the consequences of these twin processes of big data-based valuation (of individuals) and value extraction (from individuals) for social stratification, on material and symbolic dimensions. These new market lenses, and especially the self-quantification tools they rely upon, are also presented, and experienced, as a moralized system of opportunities and just deserts. They act back on people in the form of personal experiences, 
behavioral injunctions, and forms of regard and disregard.

\section{DATA'S PAST AND FUTURE}

The current growth and increasing reach of automated decision-making inevitably brings to mind earlier forms of sorting and scoring in markets. Those techniques were more rudimentary and time-consuming, but they worked on similar principles. Modern forms of information processing are 'the most recent installment in the continuing development of the Control Revolution' that began in the nineteenth century in both state offices and corporate firms (Beniger, 1986, p. 435). Likewise, the 'algorithm' is nothing new. Max Weber, for instance, discussed the step-by-step, distributed and nominally objective procedures for selection and sorting that characterized decisionmaking in modern bureaucracies.

Weber saw that capitalist markets and bureaucratic organizations shared an affinity for the systematic application of rules and measures that make the world legible so it can be acted upon. In the nineteenth century's credit market, for example, American rating agencies developed methods to identify good credit prospects. They collected bits of information about the economic reliability of individuals and corporations. Arbitrary as it often was, the use of this data to 'place firms in a clear set of ordinal categories' created the impression of precision and order within the market (Carruthers, 2013 p. 533). Agencies got better at it as time went on. The information used to produce the rating was standardized. The ordinal scheme on the output side became more refined, too, allowing for more categories of creditworthiness. Around the country, specialist organizations compiled and circulated local lists of businesses or individuals to subscribers, providing addresses and occupations, along with numerically or pictographically coded information about their qualities as potential debtors (see, e.g. The Credit Guide Company, 1889). Classes of people, scores and prices became closely connected.

The same process happened in other domains, too. Life insurance companies were 'among the first companies to seek profit from data processing: New York Life ... adopted about 1903 the nation's first numerical insurance rating system, with values assigned to various factors affecting the insurability of patients' (Beniger, 1986, p. 422). Because of the difficulty of storing and circulating individual-level information, it was often aggregated to construct broad, population-wide summaries. Regional maps and statistical graphs allowed for the development of ideas about-and control overdemographic aggregates (Zelizer, 1983, p. 86; Bouk, 2017). From the beginning of the twentieth century to the 1970s, individuals were slotted into statistical distributions, from IQ scores to the Scholastic Aptitude Tests, and apprehended not through category membership but through percentile location. Increasingly, however, what stands 
in for the individual (one's 'data double' so to speak; Bouk, 2017) is not an aggregate, or a position in a statistical distribution, but a precise set of digital records, drawn from a wide range of sources and allowing for customizable scoring possibilities. This regime returns to the promise of the painstakingly collected, and often highly subjective, personal record of the nineteenth-century credit report-except the new record is much, much more exhaustive, its components are processed automatically, and it circulates with much greater ease across institutions and markets (Marron, 2009).

So while the use of data and rules for calculation and prediction is old, there is something new under the algorithmic sun. Aggregate analyses and individualized records can now be managed at once. Data collection takes place continuously and has the potential to follow individuals indefinitely. (Even erroneous records can be very difficult to erase.) The market has become a classifier. Personal records and the scores and categories derived from them are tradable objects. Other sorts of stateproduced records, nominally public but practically inaccessible at large scales, have also been brought into the sphere of the market. Court filings, voter information, driver data, property records, city fines-all have been repurposed to feed the everexpanding appetite of private agencies and data brokers who re-sell them to third parties, including, sometimes, the state itself. These classificatory activities have also been automated, obscuring the role of human intermediaries. If the recorded individual has come into full view, the recording individual has faded into the background, arguably to the point of extinction. A machine or 'deep' learning system may decide for itself which general rules and variables to use for prediction, in a manner that is opaque to most of its users (Burrell, 2016). Engineers experiment constantly to refine their methods, and now the machines experiment, too. The basis upon which people are being scored, rated and evaluated is less predictable, or even knowable, to most of those who rely on it.

To anchor the processes we have in mind with tangible examples, consider three cases from the new era of data collection and analysis: the Snowden revelations, the rise of broadly actuarial methods of rating and scoring consumers, and the controversy over social media firms experimenting on their users. These are of course different in many ways. But they help us capture the fundamental sequence of these processes, which goes something like this: First comes a dragnet that produces a wealth of data, then algorithmic methods that allow for efficient classification and analysis, and finally the desire and ability to intervene one way or another.

\subsection{Dragnets}

In June 2013, Edward Snowden, a specialist working for the US National Security Agency (NSA), leaked a mass of classified documents revealing the global surveillance activities being carried out in the name of US national interests (Snowden, 2013). The 
dominant interpretation, particularly on the left, was that the revelations provided evidence of massive government intrusion into people's private lives-a touchy subject in every country, but especially in the USA. The moral aspect of technological overreach is clear in the case of spying, as the issue can be straightforwardly framed and litigated in terms of American legal protections against unwarranted searches, and arguments about the limits of executive power and government bureaucracy. Within this principled debate, there was also a more pragmatic disagreement about the actual utility of the information collected. While the scale and scope of surveillance data exceeded the fears of all but the most paranoid critic, the ability of officials to meaningfully analyze it was much less clear, in part due to its sheer scale. News of security analysts swimming freely in a vast sea of personal data raised problems about the combination of technical methods, moral classifications and organizational power.

\subsection{Scores}

The gradual expansion of tracking, rating and scoring in everyday life has taken place more publicly and with less fanfare. In contrast to the NSA's encroachment on individual rights, the canonical case of credit scoring can be seen in part as an unanticipated consequence of anti-discriminatory efforts in housing, retail and other markets (Poon, 2013). In the early 1970s, older, piecemeal credit-rating systems were overhauled in response to federal mandates forbidding the use of irrelevant categorical information (such as race, sex and marital status) in the process of loan qualifications, especially mortgages. Instead, the systematic collection of individual-level data about people's consumption and savings habits allowed for the consolidation of credit scoring and analysis methods that went beyond decision-making based on representative characteristics-or, less politely, stereotypes—and thus complied with the law. By the 2010s, what Rona-Tas (Forthcoming) calls 'off-label' use of credit scores or credit reports had become common in decisions to hire, rate, rent, discharge or socialize. As Rona-Tas goes on to note, by affecting people's position on the labor or housing market, these off-label uses feed back into the future calculation of scores in a process of 'turbo-performativity'.

As with the information dragnet, the question of the ritual application of scoring arose for experts as well as the laity. By allowing the segmented pricing of different 'risk categories' of borrowers (rather than simply their exclusion from the mortgage market), the credit score triggered a rapid and massive expansion of borrowing (Poon, 2009; Fligstein and Goldstein, 2010; Fourcade and Healy, 2013). In the aftermath of the 2008 financial crisis, it became clear that, when convenient, these technical tools

might be used in a ritual fashion rather than applied as designed. Data may have 
been abundant, but accurate knowledge remained sparse (MacKenzie, 2011). ${ }^{1}$ The financial meltdown also showed the persistence of moralized classifications within this system. The crisis was blamed on some combination of spendthrifts, irresponsible speculators and mortgage dealers, and the financially illiterate poor.

\subsection{Interventions}

With dragnets and scoring methods increasingly in place, the leading edge of technical development is behavioral intervention. This issue was thrown into sharp relief when a research paper reported an experimental investigation by Facebook (and an academic collaborator) of whether emotional contagion could be induced to spread through friendship networks in social media (Kramer et al., 2014). The effect of the experimental manipulation was very small. The backlash was rather larger. Social media and other digital firms run tests on their users all the time, in the sense that they try out new features or layouts or shift material around in order to see what works best, nominally for the benefit both of users and the company. But by running this investigation explicitly as an experiment, and by publishing it in an academic outlet, Facebook seemed to be interfering with the emotional lives of their users in a way that critics found repellent. The question of the actual quality of the data arises here, too. The desire of firms to experiment on their own user base is driven mostly by their need to develop accurate, effective and socially acceptable services in a way that benefits the company. If matching is poor, if brokered rankings can be gamed, or if subtle behavioral interventions fail or provoke annoyance, then they will fail in their goals.

\section{SEEING LIKE A MARKET}

We now develop a framework to help us understand the convergence of dragnets, scores and interventions. Our first intuition comes from neo-institutional theory. Organizations draw powerful injunctions from their broader institutional environments about what they should look like and do. Satisfying these institutionalized myths takes precedence over the 'demands of work activities' in the formal structure of modern organizations (Meyer and Rowan, 1977, p. 341). The myths themselves have various sources. Meyer and Rowan (1977, p. 344) mention professions, programs and techniques. The injunction coming from professions is normative and moral: we do these things because we must. That coming from programs is mimetic, taking the whole environment into account: we do these things because everyone else does. But the

\footnotetext{
${ }^{1}$ Similar problems and challenges have been noted by the engineers and data scientists responsible for managing and analyzing the largest bodies of private-sector data now available, such as those belonging to Facebook (Taylor, 2014).
} 
institutional command coming from technology is the most potent of all: we do these things because we can. Data collection in modern organizations bears this ceremonial character to a high degree. Professionals recommend, the institutional environment demands, and technology enables organizations to sweep up as much individual data as possible. It does not matter that the amounts collected may vastly exceed a firm's imaginative reach or analytic grasp. The assumption is that it will eventually be useful, i.e. valuable. The semi-structured data that sit on a firm's servers (e.g. online chats, phone conversations, images) will gradually be made usable through improvements in-for instance-semantic analysis, voice recognition or image processing and through the development of data fusion platforms. Weber (1998) remarked that technology does not need a purpose. It is its own purpose. As we have seen, modern formal organizations have long had this tendency. But at various times, technical advances of one sort or another have transformed either the quantity of information that can be collected or the quality of analysis that can be performed. Contemporary organizations are both culturally impelled by the data imperative and powerfully equipped with new tools to enact it.

The second step in the argument invokes the sociology of judgment, particularly moral judgment. Here, society is the site of 'classification struggles'. These are symbolic conflicts aimed at 'transforming the categories of perception and appreciation of the social world and, through this, the social world itself' (Bourdieu, 1984, p. 483). But in contrast to Bourdieu, and in an effort to account for the social changes wrought by the generalization of digital records, we consider the technological and specifically actuarial dimension of these struggles. In Bourdieu's analytical framework, individuals accumulate intangible forms of symbolic capital from their social position and social trajectory. We suggest that they may also accrue 'übercapital', a form of capital arising from one's position and trajectory according to various scoring, grading and ranking methods. We use the term 'über' to denote the meta-, generalized or transcendent nature of this capital. It is partly derivative of traditional forms identified by Bourdieu (e.g. economic, cultural, social, symbolic), and partly autonomous from them. The various forms of übercapital are bestowed upon individuals algorithmically, often in a manner opaque to them (Burrell, 2016). The term über also connotes something or someone who is extraordinary, who stands above the world and others in it, as inNietzsche's (2006) concept of the Übermensch. ${ }^{2}$ Übercapital is routinely understood and mobilized as an index of superiority. (An example would be the use of credit reports by employers or apartment owners as an indicator of an applicant's 'trustworthiness', for instance.) As a consequence, übercapital can have strongly re-

${ }^{2}$ More whimsically, "Uber" also evokes the cab company that rates both drivers and customers, presently one of the most high-profile firms with the sort of "interface" model of operation we are discussing here. 
active or performative effects on individual behavior, as malleable ordinal measures usually do (Espeland and Sauder, 2007; Healy, 2015).

Third, we draw on the sociology of commensuration and valuation. While the notion of übercapital helps clarify the dynamics at work, it is insufficient to explain why and how the accumulation of this particular type of capital is important. Data gathered are fed back into organizational systems and processed to produce real consequences, usually as differentiation in terms of service, products on offer and prices. Certain kinds of information (about key events such as a pregnancy, a move, or an imminent divorce) are especially valuable—and priced accordingly — as they allow for potentially lucrative reclassification and targeting of individuals. This process of sorting and slotting people into categories and ranks for the purpose of extracting some form of material or symbolic profit generates classification situations. As we explain below, classification situations and übercapital may be empirically connected but their principles of operation are quite different. Übercapital measures a resource to be deployed in a range of circumstances, or an individual's performance on a series of ordinal scales, whereas classification situations are produced with respect to market outcomes and value extractability. Someone with very low übercapital may actually be very valuable from the point of view of their classification in the market. For instance, companies may pay dearly to acquire lists of people with gambling problems, or chronic diseases requiring medication (Harcourt, 2016). Value extraction-or valorization-is partially decoupled from valuation (Vatin, 2009).

\section{THE DATA IMPERATIVE}

In large societies, the possibility of generating traceable, long-term data at the individual level requires the intervention of the state. In the USA, the government contributed to the infrastructure of individualized data in two quite different ways. First, the Social Security Number (SSN) established a means of persistently identifying individuals. Launched during the New Deal, and originally intended only as a means of allowing the Social Security Board to track the earnings of people who worked in jobs covered by the Social Security program, SSNs gradually became a de facto national identification number for American citizens and residents.

The process took about 60 years. At every stage, the government insisted that it was not interested in developing a national ID system. The Internal Revenue Service began using SSNs for tax reporting in the early 1960s. Various state agencies followed: Medicare in 1965, the military in 1969, and-in 1970-banks, savings and loan associations, credit unions, and securities dealers were required by law to collect the SSNs of their customers. This expansion continued through the 1980s, eventually connecting to all interest-bearing accounts and most government programs, as well as 
extending to new classes of persons, such as temporary and permanent resident aliens. By the early 200os, the SSN was ubiquitous (Social Security Administration, n.d.). It provided a means of tracking individuals in a consistent fashion across institutional settings and their associated records, and it was vital to the practical construction of a credit reporting system that could go beyond the scope of data collected by individual banks about their account holders.

Quite separately, and later, the state invested in the creation of the Internet. The US federal government supported the development of a network infrastructure for computer communication and directly funded or coordinated the establishment of core communications protocols such as packet-switching networks (Abbate, 2000). The state promoted the open standardization through which the technology was able to flourish at first: 'At its heart, the Internet is just a system of protocols and information exchange rules that all computers involved recognize. ... The federal government encouraged a stream of free, quickly shared software that promoted continual innovation on the network' (Newman, 2002, pp. 24-25; also see Angwin, 2014, Block and Keller, 2016).

The conjunction of these projects helped create the possibility of reliably tracking individual activity across open networks in a way that could be connected to both private financial circumstances and interactions with the state. The Internet's infrastructure is fundamentally about the identifiability of bits of information traveling to and from particular devices, not individual users. But with that in place, subsequent developments allowed for the creation and monitoring of all kinds of more or less stable identities over time, from unnamed but reliable patterns of activity originating with particular devices to known, named users and their accounts. The facticity of 'the user' varies widely. An account may be backed by nothing at all, or by an email address (which could mean anything); but perhaps also by a name, an address, a telephone number, an associated credit card, or an official government identity, which are altogether more identifiable. Unique identifiers such as these serve as anchors for personal data that might be collected from or matched to other sources. What matters is having a system whereby individuals can be reliably identified and their status rapidly queried, keyed, or merged as needed. The state played a key role in establishing the conditions for the rapid circulation of individual-level information in this way.

The piecemeal development of traceable markers of identity and the open character of the Internet's evolving infrastructure created persistent ambiguity about the character of 'online identity' and its connection to individual selves (Turkle, 1997; boyd, 2014). But whether we think 'being online' is a distinct form of sociality or simply continuous with the rest of everyday life (Jurgenson, 2011), it means leaving digital traces of your actions. From a firm's point of view, when every click or eyeball has possible economic value it is essential to keep track of who visits, how they arrived, and where they go. How much of Piketty's Capital in the Twenty-First Century have you 
read? Amazon's Kindle reader knows, and it is probably very little (2.4\% on average; Ellenberg, 2014). How long do you spend on a New York Times article before moving on? Does that time vary by section, or by day of the week? If you are a registered user, the Times knows, even if you do not. Not all information is passively collected. Ratings, comments, recommendations, connections to peers, all are cheerfully fed to companies. This is by now such a well-established niche that an economy of advice intermediaries flourishes, from Tripadvisor to Yelp. Their market power depends on the collective wisdom of the crowd, donated pro bono.

Organizations believe they should be in the data collection business, even when they do not yet know what to do with what they collect. That is the ceremonial aspect of the data imperative. If a firm is not sure how to extract its value, there are other organizations that know, or claim to know. At the core of this process are data brokers (Hoofnagle, 2003; Federal Trade Commission, 2014) and data-fusion firms, such as Palantir. These companies purchase, mine or work on data from a vast range of sources, including the proprietary records stored in the clients' data dumps. They merge, process, summarize, clean and categorize, for the purpose of producing usable lists, or increasingly refined individual profiles, for interested parties (Herbert, 2016). On the consumer-facing side, meanwhile, it is increasingly inconvenient to navigate a retail Web site without being prompted to sign in via a social media account. More than anyone else, Google and Facebook have learned to exploit the stream of data released by billions of users to produce marketable consumer targeting. Google is essentially an advertising company, with Ad revenue just shy of $90 \%$ of its total as of 2014. Facebook's revenue stream is also almost entirely ad-driven.

In the early to mid-200os, at the beginning of the second expansion of free-tojoin but centrally administered services, this outcome seemed unlikely. How could any network ever grow big enough to encapsulate most people's online experience? After all, the web had triumphed over precursors like CompuServ and AOL because it was open and decentralized. Beginning around 2010, the idea of 'big data', and its handmaiden 'data science', came to summarize what was happening on the corporate side. The prospect of data from a new generation of wearable devices and sensors provoked a further round of speculation about how a new 'Internet of Things' will change our lives one way or another, whether by allowing you to track your fitness workouts or passively recording data that might be of use to your insurance company (Howard, 2015; Neff and Nafus, 2016). As the scope and depth of data collection has expanded, it is no wonder scholars began to put away their Goffman, the touchstone of early sociological efforts to understand online interaction, and reached for their Foucault instead.

But Marx and Weber lurk here, too. Once collected, personal information is used to sort and slot people into actuarial categories, predicting the probability of loan repayment, the likelihood of healthy behavior, the prospects for good job performance, 
or criminal recidivism (Barocas and Selbst, 2016). 'A person's on- and offline activities are turned into scores that rate them above or below others' (Citron and Pasquale, 2014, p. 3). The goal is to make a profit by commodifying people's behaviors (defined through measurements), their tastes and, increasingly, their social relations. This desire to better score and rank users on multiple dimensions, and the subsequent linking and integration of measured profiles across domains, creates the possibility of übercapital.

\section{4. ÜBERCAPITAL}

Viviana Zelizer $(1997,2011)$ argued that people mark their relations to one another through their differentiated use of money. They look for 'good matches' between forms of payment and categories of persons, to use money in a way that feels morally right. A gift card is not the same thing as giving someone cash. Institutions, too, work to find means of payment that mark the relationships they index. Food stamps are not the same as cash subsidies.

Zelizer's concepts of 'earmarking' and (more recently) of 'good matches' establish a degree of agency in these processes. They are the sometimes habitual and pragmatic, sometimes self-conscious and strategic features of the 'relational work' that people enact in their everyday economic life. Building on Zelizer, Levy (2013, p. 75) suggests that earmarking also goes on in digital life: 'people constitute and enact their relations with one another through the use and exchange of data. Consider, for example, a person who monitors the real-time location of her friends via a smartphone app designed for this purpose. By monitoring some friends but not others, she differentiates among her relationships, defining some as closer'. But, conversely: what if our use of money (and our data) marked us, instead-whether we intended it or not-and in a way that facilitated resource extraction? What if this all happened in the background? Increasingly, the social life of money is less a matter of deliberate fine-tuning by individuals enacting thick moral relations, and more a matter of profit for firms overfed with data.

\subsection{Capitalizing on the habitus}

Companies seek good matches when they want to link a wealthy customer with a quality credit card, or a heavy drinker with a bad insurance plan. This kind of matching capitalizes on people's differentiated dispositions and practical habits, what Pierre Bourdieu calls their habitus. The 'good matches' are perceived as natural because they fit well with how things already are. Past and present social positions, social connections and ingrained behavioral habits shape not only people's desires and tastes, but also the products and services pitched to them. Much of economic life is already structured this way (Bourdieu, 2005). A working-class person is more likely to walk into a 
Walmart than a Bloomingdale's, and to interact there with a clerk who resembles her. But when markets see, this matching feels all the more natural because it comes from within-from cues about ourselves that we volunteered, or erratically left behind, or that were extracted from us in various parts of the digital infrastructure. Aspects of the habitus, refracted through the classificatory system and recorded for analysis, are publicly revealed through these mechanisms. At the same time, they undergo a process of private appropriation.

This process creates forms of social advantage and disadvantage that sociology is ill-equipped to think about. Capital, as Bourdieu (2006, p. 241) puts it, is an embodied set of resources which allows its bearer to 'appropriate social energy' by making him fit naturally into the dominant social group-the rich, for example, or the cultured. Particularly in its symbolic forms, capital takes time to develop and accumulate. Although it can be deliberately acquired, it is better if it appears natural and effortless. This makes deep, early family socialization the most efficient vehicle for capital's transmission, particularly in its immaterial, symbolic form. When embodied as second nature, capital tends to 'persist in its being' and reproduce itself 'in identical or expanded form'. The longer the habituation, the more second-nature and embodied it is.

In Bourdieu's framework, capital has a material dimension in the form of income or wealth, and a cultural one in the form of familiarity with dominant tastes. Its two principal derivative forms are social and symbolic capital. The former is a durable network of interpersonal connections that can be effectively mobilized. The latter is institutionally legitimated competence and authority. Bourdieu insisted-and critics have often complained-that cultural capital and symbolic capital are not easily measurable. In his view, they are primarily known by their effects, that is, by the extent to which they allow actors to accrue specific material and symbolic profits, such as money, power or authority. This lends the Bourdieuian approach a flexibility of application that skeptics feel makes a virtue of endogeneity.

As a metaphor, capital is by now both ubiquitous and a little threadbare. Over the past decade, social theorists have enthusiastically capitalized any bit of social life where there seemed to be some inequality and a little competition, from good books to good looks. Do we need another form? Übercapital overlaps with the traditional forms identified by Bourdieu but also departs from them. It has a clear materiality, and a numerical form. It is accumulated over the long history of a person's recorded actions, built up from traces left on everything from social media to credit bureaus, shopping Web sites and fidelity programs, courthouses, pharmacies, and the content of emails and chats. It incorporates social ties (now measurable through the value of one's social network) and moral worth (a quantified appreciation of one's 'trustworthiness' or 'accountability'). It is subject to calculation. Whether the analyst examines network centrality, fits linear models, or reduces a multidimensional space to its underlying features, the algebraic methods used seek to "reduce", "project", or "char- 
acterize" the data through the calculation of eigenvalues and eigenvectors. Thus, an equally apposite name for this ubercapital might be 'eigencapital'.

Its materiality makes übercapital a contingent empirical phenomenon-something of great potential power, but also a genuine engineering problem subject to failure or incomplete realization. We can think of übercapital as made up of all the digital information available about an individual, encapsulating the totality of her relations as expressed through digital traces, ordered and made tractable through scoring and ranking methods. In the Bourdieuian manner, it is visible through its effects. Advantages accrue to those who accumulate it, such as better prices, better service, kinder consideration and higher standing across markets.

At present, übercapital exists mainly in potentia. For it to come closer to what we have in mind, each of the tendencies we outlined in our opening vignettes would have to fuse into a more encompassing system of techno-social measurement. Übercapital tends toward the scope of the NSA's dragnet, the unifying organizational nexus of the credit score, and the technical capacity of a Facebook or Google, to intervene and offer choices or locally match individuals on the basis of large volumes of properly analyzed data.

Such systems are already highly integrated on the financial side, where specialized firms rely on oddly sourced data to obtain a more 'rounded' view of their most elusive, marginal customers. A technically and organizationally unified approach to tracking and scoring individual behavior thus already has a practical, work-in-progress reality. It began in the world of finance for good reason. In the same way that economic capital, expressed and usable directly in monetary terms-the literal currency of material life-tends to be the main (or primary) axis of organization and power in society, übercapital also harkens back to familiar economic traits. The high achievers in the scoring economy also tend to be the high achievers in the real economy.

Conversely, the poorest members of society tend to be beyond the reach of the most advantageous scoring and classification schemes, while being often the targets of the most potentially harmful forms of data surveillance and value extraction (Waddell, 2016). That efforts have been made to incorporate the poor through creative and unusual indicators should not obscure the structural determinants weighing on their position. Society's most vulnerable citizens still represent the largest segment of the 'lumpenscoretariat' whose resources are below the threshold of interest of even predatory lenders, and whose economic lives have to be carried out almost exclusively in the cash-only and informal economies (Fourcade and Healy, 2013).

\subsection{The fetishism of data and the secret thereof}

Like other forms of capital, übercapital has a moral aspect. It is defined against particular standards of behavior, which its promoters and users see as desirable. The 
process of incorporation is the key. People must be visible, and available for measurement. Karl Polanyi (2001) argued that the commodification of labor achieved by the dismantling of the Speenhamland system in the early nineteenth century was a prerequisite to the rise of modern capitalism. The political and economic project was to make individuals - individual bodies, i.e. labor power-free, movable and available to capital. To be a worker then was to be free to contract out one's labor. So the rising capitalist state actively dismantled rural society. Now, rather than individual bodies being made free to roam the British countryside, so that their labor power might be directed toward factories, individuals are invited to roam the web, so that their behaviors and characteristics can be harvested (Huws, 2014). Citizens in the cloud economy are trackable and tractable. Those who are invisible are of little use. The profitability of digital consumer identities is such that it is almost impossible to disappear once one has been incorporated. Permanent deletion of data may not be an option. Many companies keep users maximally visible by integrating their services under a single user profile. ${ }^{3}$ It used to be that the state was the only organization with the resources to identify and track individuals across many contexts and settings. No longer.

The cultural formations around übercapital tend to obscure its workings. To paraphrase Marx, while a score appears, at first sight, a trivial thing, in reality it abounds in metaphysical subtleties. Marx argued the analysis of commodities required a journey to the 'mist-enveloped regions' of religion. We look instead to the cloud, where social relations between people assume the fantastic form of database relations between an Internet of Things. These products, not now prices but scores, appear as autonomous figures endowed with a life of their own, a fetishism of data rather than commodities.

Thus far, the politics of übercapital has been rather tame. Earlier efforts by wouldbe philanthropists and social reformers focused more on better preparing individuals to fit the system's expectations, rather than on challenging it. Considerable public and private energy has gone into helping people optimize themselves toward this end, from lending circles designed to trick the Fair, Issac and Company (FICO) scoring game (Wherry et al., 2014), to credit seminars, to financial literacy and self-help services (Fridman, 2016). Little by little, the components of übercapital are becoming sites of personal investment, whereby individuals learn to become 'entrepreneurs of themselves' (Foucault, 2010). However, a reaction-the prelude to a Polanyian 'counter-movement'? - is emerging around the propertization of personal data, and the regulation and possible prohibition of certain big data practices. Examples of the latter include the right to be forgotten online, confirmed in a landmark decision by the European Court of Justice in 2014, and the sweeping data privacy reforms adopted by

\footnotetext{
${ }^{3}$ This is especially obvious when companies that previously provided a heterogeneous array of services aggressively attempt to centralize, as in the case of Google+ accounts, but it is no less true of companies that grow into new markets and carry their users with them, as in the case of Amazon.
} 
the European Parliament in 2016; the demand for due process guarantees in the use of data for the purpose of typifying people (Barocas and Nissenbaum, 2015; Crawford and Schultz, 2014); discrimination and disparate impact issues in the application of digitally powered techniques (Newman, 2015; Barocas and Selbst, 2016); increased scrutiny about market dominance, particularly in the case of Facebook and Google; and finally a critique of the capitalistic 'sorting of people according to their presumed economic or political value' (Gandy, 1993).

The NSA's dragnet notwithstanding, commercial data engines still mostly capture bits and pieces of us-a conversation on Facebook, a card swiped at the supermarket, a parking ticket left unpaid, a rating by an Airbnb homeowner or an Uber driver. Their promise lies in drawing together a whole greater than the sum of its parts. What makes these pieces worth collecting and integrating is a powerful cultural abstraction-the notion of an efficient, purposive and knowable actor (Jepperson and Meyer, 2000). Around that peculiar character boundaries must be drawn, multiple identities will be typified, so that her behavior can be steered and nudged in ways both personally gratifying and economically profitable (Thaler and Sunstein, 2008). But the battle will continue to rage over who should have the right and the means to define and valorize these identities.

\subsection{Automated veridiction}

Übercapital's moral quality is forward-looking. Scores are truth-telling dispositifs, leading individuals to reveal who they really are (Foucault, 2014). Their predictions have a normative as well as an empirical component. Individuals who deviate from behavioral expectations raise flags signaling possibly illegal behavior. Again, the examples may be familiar. Take the case of buying something far from where you live. An automated system decides something is out of order and your card is declined. The consumer will complain that their card company is not smart enough to understand that airplanes allow rapid travel around the country. But the card issuer's desire to avoid fraud seems reasonable, too. Ideally, you would like the company to recognize and preempt all and only bad charges, with no false positives. The execution is lacking, which creates demand for better methods. Across all customers, the system needs a way of learning what a pattern of, say, occasional business travel looks like. For any particular customer, it needs the ability to properly classify them with respect to that pattern. Or better, a way of managing the identification process so that uncertainty about who is using the payment system is minimized.

Catching 'spending out of place' presupposes a social model of consumption. Fraud monitoring systems check where and what you are buying, and decide whether it seems right for you. Excessive purchases of expensive consumer durables such as TVs, game consoles or stereo equipment are a familiar trigger. But things need not 
stop there. One of the authors had a credit card transaction denied while trying to refill her car's gas tank in a high-poverty Oakland neighborhood. The clerk indicated with resigned anger that the location of his gas station was the likely cause of the problem. Back in Berkeley a few minutes later, the card worked without a hitch. The taste profile that implicitly lies behind the fraud alert is depressing, but was also fit for purpose. The idea that one's card company has both a theory of taste and a model that classifies you within it is not much of an exaggeration. Visa's security system helps keep a social boundary in place.

The edge case of spending out of place is the effort to be no place at all. In a clever self-experiment, sociologist Vetoes (2014) went to great lengths to leave no digital traces of her pregnancy. She paid as much as possible with cash, avoided electronic transactions, and prevented friends and relatives from discussing the matter on Facebook and similar locations. For our purposes, the most interesting moment happened when her husband went to a pharmacy and tried to buy $\$ 500$ worth of Amazon gift cards with cash. (They wanted to use the cards to buy a stroller.) He was told that the store was legally obliged to report excessive cash-to-card transactions to the authorities. When a middle-class person tries to spend cash in this way-and in $\$ 500$ chunks-then, to put it in our terms, they appear like a member of the lumpenscoretariat. And the now-automated social inference is that this kind of spending is often criminal.

The sociological difference between the convenience of electronic transactions and the convenience of cash transactions brings out übercapital's moral dimension. Classically, cash is the most liquid, easy to use and universally accepted form of payment. But its flows are hard to trace. The many informal means of bestowing moral content on monetary transactions involve marking and dividing it into categories based on particular relationships (Zelizer, 1997). Similarly, the security of cash transactions has in everyday life been guaranteed not by real or implied legal contracts but by the trust in social ties (Macaulay, 1963). In a system that becomes übercapitalized, however, the goal-and the main business and engineering problem-is to make electronic systems of payment as or more convenient as cash while preserving a full transaction record for subsequent analysis and organizational feedback.

Cash exchanges create problems of trust and malfeasance that people manage through direct social ties, norms of exchange, and reputational or moral economies. These processes have been the meat and potatoes of economic sociology for the past 30 years. But electronic systems transmute these interactional processes into quantitative data. The well-situated consumer feels the benefits directly. Her reputation is no longer confined to a local community of peers. The trust she feels confident extending is no longer circumscribed by her social network. Instead, she carries it with her in her handbag. Moreover, to the extent that it works successfully-and as we have been emphasizing, getting it to work is a huge challenge-the process fades into the back- 
ground. The ideal, in fact, is much like the NSA's defense of its own methods. You do not see the bad actors who tried to use your card but were automatically denied. You do not have your integrity questioned by a sales clerk. When things go wrong, these systems seem stupid, rigid or rule-bound. But when they work, they smooth the way by preventing fraud, enabling good matches and helping people make good choices. This is experienced by the fortunate consumer as a well-deserved kind of ease. In a way, the infrastructure of übercapital revives an old kind of privilege. It promises the portable, universally recognized trustworthiness and good reputation of the gentleman abroad, sustained by his word and a letter of introduction, in a newly quantified and nominally democratized form.

\section{THE NEW SPIRIT OF CLASSIFICATION}

In practice, Übercapital does not boil down to a single measure. Value scales are not unified across its various contributory factors, and so the parts do not fully cohere. This is more than just a matter of variability in measurement. Scores and ratings are market-derived and market-oriented. They are always sliced in a particular way, for a particular profit-making purpose, be it risk analysis, or marketing, or social influence. In many instances, measures are made to order, to express the value of particular types of individuals to a particular company. Thus, the general übercapital that accrues to the individual does not always align with her market value for a particular organization. As in the credit market, a person with a 'bad' score on some dimension might nevertheless be valuable for that very reason to a particular kind of company. In a system of classification situations, no one is in principle outside the market. Everyone should be able to obtain service, if the terms are right for the servicer. As long as individuals are visible, measures of risk can be calculated and the terms of a profitable exchange established. The better the data, the better firms can predict whether a person is likely to be well served by their product, even if that in effect means predicting who is most likely to be tempted by a bad or exploitative deal.

These processes affect class formation. New social divisions are emerging, fueled by stratifying technologies at work within the market itself (Fourcade and Healy, 2013). Ordinal and cardinal scales (e.g. credit score, mileage count, loyalty points) are broken down for the purpose of market-making: prime or sub-prime; trusted or untrusted; Platinum, Gold or whatever combination of thresholds and cut-points in the continuum seems sensible or profitable in any particular case. Because this approach is internal to the market and inductive, it tends to make the traditional first questions of class analysis moot. We need not argue a priori about the conceptual basis of class taxonomies, or about which classification situations will always and everywhere matter. Nor can we inherit and partially aggregate the official system of occupational 
classifications laid down by the state. Rather we must investigate the classification schemes induced by the market itself. These schemes, we contend, have reactive or performative effects on individual behavior, on organizational strategy, and on people's life-chances.

For Weber (1978, p. 182), while the distribution of property or skills is the precursor to class formation, 'the kind of chance in the market is the decisive moment which presents a common condition for the individual's fate.' Class members are constrained in the same way by market exigencies. Hence, he claims that classes arise when 'a number of people have in common a specific causal component of their life chances' and that 'class situation is ultimately market situation'. The traditional challenge for this approach has been to establish the categorical class situations that flow from the distribution of property, skills, and other resources people bring to the market, usually conceived as the labor market. We emphasize instead the market's own efforts to classify the people inside it - to identify them as members of some class, to offer prices and other opportunities on the basis of that membership, and to reconfigure both the criteria for class membership and the overall system of categories in the effort to maximize returns from consumers, productivity from employees, value from online passers-by.

Weberian approaches to class have a tendency to gravitate away from a few comprehensible antagonistic groups toward a multiplicity of locations. It can be difficult to avoid the pull toward more categories, more fine-grained classes, and ultimately a continuum of individual combinations of property, skills and resources. Critics typically see this as a point of failure. But we might instead see Weber correctly identifying the market as the place where this process of class formation and identification takes place and is made real. On this interpretation it would be a mistake to try to identify criteria for class membership in advance. Rather, we should be looking to understand the process through which market institutions create market situations, and hence class situations, from the inside.

For Weber, an individual's life-chances (or 'fate') unfold in the conceptually distinct but practically entangled dimensions of market position, social honor and political power. Classifying techniques within markets have the potential to impact all three. Mechanized evaluations of borrowing risk fuel inequalities not only in credit access but in the terms of credit, and reverberate far and wide, affecting one's chances of housing, employment, or insurance. Differentiated marketing-targeting individuals according to the likelihood that they will be more or less receptive to particular kinds of products or ideas-presupposes a relatively immobile social order of set preferences, and may end up deepening those differences by reinforcing the behaviors that caused them to be identified in the first place. From this point of view, the economist's dream of perfect price discrimination is also the natural end point of the Weberian process of establishing market situations. 
The logic of übercapital powers this process of price discrimination. The longterm tendency has been away from efforts to 'take the temperature' of consumers or externally influence their tastes. Instead, we see ever-stronger efforts to monitor the actual behavior of consumers from inside the market itself. Advertising remains a huge business, but the age of generic and even 'niche' marketing is slowly coming to an end. It is being replaced by properly individualized services that nevertheless are structured and classified from the vendor or provider's point of view. Cases where firms know what you want, or are likely to do, are presently associated more with markets for services than consumer durables. In the paradigmatic cases, things seem to work by magic. You tell your phone you want to go somewhere, and a vehicle appears a few minutes later. You do not even have to talk to the driver. This seamless satisfaction of particular wants is pleasing, and increasingly common. Successfully anticipating new needs, desires, and plans before they are fully formed is very much harder, but it is the goal to which these systems aspire.

The old classifier was outside, looking in. The firm tried to guess what you liked based on some general information, and often failed. The new classifier is inside, looking around. It knows a lot about what you have done in the past. Increasingly, the market sees you from within, measuring your body and emotional states, and watching as you move around your house, the office, or the mall. This pushes firms away from an advertising model (even one with highly targeted advertising) toward one where people are dynamically classified, and where their existing classification situation allows for further diverse applications in the future. The new ideal is a personalized presence that is so embedded in daily routines that it becomes second nature.

The empirical questions this approach raises are correspondingly different. First, we will need to know much more about how classification situations are coded and operationalized. This implies the study of practical methods, their historical development and their operational potential. Second, we need to learn how sorting procedures are implemented and experienced in practice by actors on both sides of the market. And third, if classification situations are associated with differentiated market positions, we must ask what are the stratification outcomes for individuals so classified, both in structural and phenomenological terms. These effects go beyond the market, too. As digital systems become true platforms for social interaction encompassing substantial segments of the world's population, their ability to measure and intervene in activity spills over into political, civic and social life.

\section{CONCLUSION: THE ECONOMY OF MORAL JUDGMENT}

We have come a long way from the 'cyborg dreams' of the 1950s, where social life (and social theory) was destined to be replaced by calculating automata or 'think- 
ing machines' (Mirowski, 2002). Today, a new behavioralism challenges the assumptions that dominated economics and political science in the cold war period (Amadae, 2003). Acrimonious debates about the calculative abilities of individuals and the limits of human rationality have given way to an empirical matter-of-factness about measuring action in real life, and indeed in real time. The computers won, but not because we were able to build abstract models and complex simulations of human reasoning. They bypassed the problem of the agent's inner life altogether. The new machines do not need to be able to think; they just need to be able to learn.

Correspondingly, ideas about action have changed. When people are presumptively rational, behavioral failure comes primarily from the lack of sufficient information, from noise, poor signaling or limited information-processing abilities. But when information is plentiful, and the focus is on behavior, all that is left are concrete, practical actions, often recast as good or bad 'choices' by the agentic perspective dominant in common sense and economic discourse. The vast amounts of concrete data about actual 'decisions' people make offer many possibilities of judgment, especially when the end product is an individual score or rating. Outcomes are thus likely to be experienced as morally deserved positions, based on one's prior good actions and good taste. That this is an economy of moral judgment is easy to apprehend when it appears outside of the market. Recent reports of nascent 'social credit' or trust-based scoring methods in China, for example, caused a chill to run down the spines of some of the Fitbit wearers feeding information into the 'data lakes' managed by US firms (Cegłowski, 2015).

As digital traces of individual behaviors are aggregated, stored, and analyzed, markets see people through a lens of deserving and undeservingness, and classification situations become moral projects (Fourcade and Healy, 2007). Because they seem to record only behavior and behavior is seen to flow from conscious choices, scores become ethically meaningful indexes of one's character. Hence, the nervousness that accompanies the credit check at the car dealer or the appliance store. With access to our most intimate and unconscious behavior, new digital tools make a new economy of moral judgement possible. Passive records are turned into active metrics, which imply calculation, efficiency, and the obligation to be in control of and accountable to oneself. Metrics become moral injunctions. Spend, but in a controlled way. Drive, but not too fast. Eat, but stay healthy. The prosthetic rationality of the Fitbit or the score offers benevolent surveillance, implicitly instructing people to self-monitor and, if necessary, reach higher or turn their lives around.

An übercapitalized world is an economy of differentiated moral judgments where distinctions regarding good behavior become an economic structure of opportunity. The moral structure grafts itself onto the economic structure by way of people's dispositions and choices. Bad outcomes are nothing but the mechanical translation of bad habits and behavioral failures. Bad luck in missing a payment, or good fortune in 
having a parent who will pay a bill, get coded as poor or wise personal choices. One's score falls or rises accordingly. The method seems dispassionate, impartial and objective. As a result, the principle by which people become economically qualified or disqualified appears to be located purely within them. Everyone seems to get what they deserve. Eschewing stereotypes, the individualized treatment of financial responsibility, work performance or personal fitness by various forms of predictive analytics becomes harder to contest politically, even though it continues to work as a powerful agent of symbolic and material stratification. Übercapital subsumes unlucky circumstance and uncaring structure into morally evaluable behavior (Fourcade and Healy, 2014, unpublished).

Or so we claim. Will these tendencies be fully realized? Obviously, we do not know. In practice, what we have are fragments, shreds and patches of a possible future. The obstacles to its full implementation are substantial. Technology often does not work as promised. Scoring systems are blunt instruments. Big data may produce small insights. Far from a multidimensional cloud of data readily available for use by consumers and companies, in practice we end up with absurd product recommendations, bizarre Facebook ads and terrible dates. Still, the volume of engineering resources presently being directed at these problems is astonishing, and the massive diffusion of cheap, connected devices is unprecedented. Sociologists should think carefully before simply asserting that implementation problems will not be solved in something like the manner that the main players are driving toward.

It is hard to say what the near future holds. Increasingly, individual-level data can be collected and connected by firms to generate more fully rounded pictures of their users and customers. The idea is not that everyone will have a universally visible score literally hanging from their necks like the Äppärät-wearing citizens of Gary Shteyngart (2010)'s dystopian Super Sad True Love Story. What matters is that the infrastructure of scoring, originally built within the sphere of the credit market, is being extended and applied across many new settings and in pursuit of new market opportunities. The FICO is the most widespread means by which cross-institutional connections can be made, even as particular market actors use it in many different ways for their own ends.

Our approach therefore differs from theory that simply emphasizes individual monitoring from the outside, or internalized adjustment to some disciplining technology. Those processes are not irrelevant. Especially in the field of crime and punishment, surveillance and predictive methods are in wide use in this broadly Foucauldian sense, from ankle bracelets to risk-based sentencing (Harcourt, 2006). But markets see differently from states, and demand a different sort of analysis. We have presented a framework for understanding a system of profit-making and stratification that works through the lens of data, scores and classes, where matches and exchanges are made on the basis of individual measurements meant to capture moral categories 
such as trust, reputation, goodwill and respect on the input side, and extractability on the output side. Our focus on monetary outcomes allows us to see what states learn from markets: how to increase efficiency, how to save money, and how to better extract income. In an age of constrained budgets and fear of debt, they, too, may end up seeing like a market.

\section{REFERENCES}

Amadae. Sonia. 2003. Rationalizing Capitalist Democracy. The Cold War Origins of Rational Choice Liberalism. University of Chicago Press.

Angwin, Julia. 2014. Dragnet nation. A Quest for Privacy, Security, and Freedom in a World of Relentless Surveillance. Times Books.

Barocas, Solon and Andrew Selbst, 'Big Data’s Disparate Impact,' California Law Review, Vol. 104: 2016.

Barocas, Solon and Helen Nissenbaum. 2015. 'Big Data's End Run around Anonymity and Consent.' Pp. 44-75 in Privacy, Big Data, and the Public Good Frameworks for Engagement, Edited by Julia Lane, Victoria Stodden, Stefan Bender, Helen Nissenbaum. New York: Cambridge University Press.

Beniger, James. 1986. The Control Revolution. Technological and Economic Origins of the Information Society. Harvard University Press.

Block, Fred L. and Matthew R. Keller. 2016. State of Innovation: The U.S. Government's Role in Technology Development. New York: Routledge.

Bouk, Dan. Forthcoming. 'The History and Political Economy of Personal Data over the Last Two Centuries in Three Acts.' Osiris (special issue on 'The Histories of Data").

Bourdieu, Pierre. 2005. The Social Structures of the Economy. Polity.

Bourdieu, Pierre. 2006. 'The Forms of Capital'. In Handbook of Theory and Research for the Sociology of Education, ed. J. Richardson, 241-258. New York: Greenwood.

Boyd, Danah. 2014. It's Complicated: The Social Lives of Networked Teens. Yale University Press.

Burrell, Jenna. 2016. 'How the Machine "Thinks": Understanding opacity in machine learning algorithms.' Big Data \& Society, January-June: 1-12.

Carruthers, Bruce. 2013. 'From Uncertainty Toward Risk: the Case of Credit Ratings.' Socio-Economic Review 11:525-551.

Cegłowski, Maciej. 2015. "Haunted by Data." Presented at Strata+Hadoop World conference, New York City, October 2015. Available at http://idlewords.com/ talks/haunted_by_data.htm. Last visited April 19th 2016. 
Citron, Danielle Keats, and Frank A Pasquale. 2014. 'The Scored Society: Due Process for Automated Predictions'. Washington Law Review 40: 1-33.

Cottom, Tressie McMillan. 2016. Lower Ed. New Press.

Crawford, Kate and Jason Schultz. 2014. 'Big Data and Due Process: Toward a Framework to Redress Predictive Harm.' Boston College Law Review 55: 93-128.

Credit Guide Company, The. 1889. The Credit Guide: a Reference Book for the Local Trade of Chicago. Chicago, IL.

Eccles, Robert G, and Harrison C White. 1988. 'Price and authority in inter-profit center transactions'. American journal of Sociology $\mathrm{S}_{17}-\mathrm{S}_{51}$.

Ellenberg, Jordan. 2014. 'The Summer's Most Unread Book is'. Wall Street Journal, July 32014 .

Espeland, Wendy Nelson, and Michael Sauder. 2007. 'Rankings and Reactivity: How Public Measures Recreate Social Worlds'. American Journal of Sociology 113, no. 1: 1-40.

Federal Trade Commission. 2014. ${ }^{\star}$ Data Brokers: A call for accountability and transparency. https://www.ftc.gov/system/files/documents/reports/data-brokers-call-transparency-accountabil 140527databrokerreport.pdf accessed on September 29, 2015.

Fligstein, Neil, and Adam Goldstein. 2010. 'The anatomy of the mortgage securitization crisis'. In Markets on Trial: The Economic Sociology of the US Financial Crisis, eds. Michael Lounsbury, and Paul M. Hirsch, Emerald Group Publishing Limited.

Foucault, Michel. 2010. The Birth of Biopolitics: Lectures at the College De France, 1978-1979. London: Palgrave MacMillan.

Foucault, Michel. 2014. Wrong-Doing, Truth-Telling: The Function of Avowal in Justice. Edited by Fabienne Brion and Bernard Harcourt. University of Chicago Press.

Fourcade, Marion. Forthcoming. 'Ordinalization'. Sociological Theory.

Fourcade, Marion, and Kieran Healy. 2007. 'Moral Views of Market Society'. Annual Review of Sociology 33: 285-311.

Fourcade, Marion, and Kieran Healy. 2013. 'Classification situations: Life-chances in the neoliberal era'. Accounting, Organizations and Society 38, no. 8: 559-572.

Fourcade, Marion, and Kieran Healy. 2014. 'Credit Scores and the Moralization of Inequality'. Unpublished Manuscript. Presented at the annual meeting of the American Sociological Association.

Fridman, Daniel. Forthcoming. Freedom from Work: Embracing Financial Self-Help in the U.S. and Argentina. Stanford University Press.

Gandy, Oscar H. 1993. The Panoptic Sort: A Political Economy of Personal Information. Westview Press.

Gillespie, Tarleton, Pablo J. Boczkowski, and Kirsten A. Foot. 2014. The Relevance of Algorithms. In Media Technologies: Essays on Communication, Materiality, 
and Society, eds. Tarleton Gillespie, Pablo J. Boczkowski, and Kirsten A. Foot, 167-194. MIT Press.

Harcourt, Bernard. 2006. Against Prediction. University of Chicago Press.

Harcourt, Bernard. 2014. Governing, Exchanging, Securing. Big Data and the Production of Digital Knowledge. Columbia Law School, Public Law and Legal Theory Working Paper \# 14-390.

Healy, Kieran. 2015. "The Performativity of Networks." European Journal of Sociology 56:175-205.

Herbert, David G. 2016. “This Company Has Built a Profile on Every American Adult.” Bloomberg. http://www.bloomberg.com/news/articles/2016-08-05/this-company-has-built-a-profile-on-ever Accessed August 15, 2016.

Hoofnagle, Christopher. 2003. 'Big Brother's Little Helpers: How ChoicePoint and Other Commercial Data Brokers Collect and Package Your Data for Law Enforcement'. North Carolina Journal of International Law and Commercial Regulation 29: 595-632.

Howard, Philip. 2015. Pax Technica. How the Internet of Things May Set Us Free or Lock Us Up. Yale University Press.

Huws, Ursula. 2014. Labor in the Global Digital Economy: The Cybertariat Comes of Age. Monthly Review Press.

Jepperson, Ronald L. and John W. Meyer. 200o. 'The "Actors" of Modern Society: The Cultural Construction of Social Agency'. Sociological Theory 18:100-120.

Jurgenson, Nathan. 2011. 'Digital Dualism and the Fallacy of Web Objectivity'. The Society Pages, 2011.

Levy, Karen. 2013. 'Relational Big Data.' Stanford Law Review 66: 73-79.

Levy, Karen. 2015. 'Intimate Surveillance.' Idaho Law Review 51:679-693.

Limn. 2012. Limn Number 2: Crowds and Clouds. CreateSpace Independent Publishing Platform.

Macaulay, Stewart. 1963. 'Non-Contractual Relations in Business: A Preliminary Study'. American Sociological Review 28, 55-67.

MacKenzie, D. 2011. 'The Credit Crisis as a Problem in the Sociology of Knowledge'. American Journal of Sociology 116, no. 6: 1778-1841.

Marron, Donncha. 2009. Consumer Credit in the United States: A sociological perspective from the 19th century to the present. Palgrave Macmillan.

Meyer, John W, and Brian Rowan. 1977. 'Institutionalized organizations: Formal structure as myth and ceremony.' American journal of sociology 340-363.

Meyer, Robinson. 2014. 'When You Fall In Love, This Is What Facebook Sees'. The Atlantic.

Mirowski, Philip. 2002. Machine Dreams. Economics Becomes a Cyborg Science. Cambridge University Press. 
Morozov, Evgeny. 2013. To Save Everything, Click Here: The folly of technological solutionism. PublicAffairs.

Neff, Gina, and Dawn Nafus. 2016. Self-Tracking. MIT Press.

Newman, Nathan. 2015. Data Justice: Taking on Big Data as an Economic Justice Issue. Available at http://www.datajustice.org/. Accessed April 5, 2016.

Newman, Nathan. 2002. Net Loss: Internet Prophets, Private Profits and the Costs to Community. Pennsylvania State University Press.

Nietzsche, Friedrich. 2006. Thus Spoke Zarathustra, ed. Robert Pippin, trans. Adrian Del Caro.

Pasquale, Frank. 2015. The Black Box Society. Harvard University Press.

Polanyi, Karl. 2001. The Great Transformation: The Political and Economic Origins of Our Time. Boston, MA: Beacon Press.

Poon, Martha. 2009. 'From New Deal institutions to capital markets: Commercial consumer risk scores and the making of subprime mortgage finance'. Accounting, Organizations and Society 34, no. 5: 654-674.

Poon, Martha. 2013. 'Statistically Discriminating Without Discrimination'. Working paper.

Scott, James. 1999. Seeing Like a State. How Certain Schemes to Improve the Human Condition Have Failed. Yale University Press.

Snowden, Edward. 2013. 'Open Letter to the People of Brazil.' Washington Post, December 17 th.

Social Security Administration. N.d. Social Security Number Chronology. https: //www.ssa.gov/history/ssn/ssnchron.html. Last visited April 13 th 2016.

Taylor, Sean J. 2014. Common Limitations with Big Data in the Field. Paper presented at the Joint Statistical Meetings, Boston, MA.

Thaler, Richard and Cass Sunstein. 2008. Nudge. Yale University Press.

Turkle, Sherry. 1997. Life on the Screen: Identity in the Age of the Internet. Simon and Schuster.

Vatin, François. 2009. "Introduction: évaluer et valoriser." Pp13-33 in Évaluer et valoriser. Une sociologie économique de la mesure. Toulouse: Presses Universitaires du Mirail.

Waddell, Kaveh. 2016. How Big Data Harms Poor Communities. The Atlantic. April 8.

Weber, Max. 1998. 'Science as a Vocation'. In From Max Weber. Essays in Sociology, eds. Hans H. Gerth, and C. Wright Mills, 129-157.

Wherry, Frederick, Kristin Seefelt, and Anthony Alvarez. 2014. 'Relational accounting and the financial self'. Paper presented at the American Sociological Association Meetings, San Francisco.

Ziewitz, M. (2016). 'Governing algorithms: Myth, mess, and methods'. Science, Technology, and Human Values 41(1). 
Zelizer, Viviana A. 1983. Morals and Markets. The Development of Life Insurance in the United States. Transaction Publishers.

Zelizer, Viviana A. 1997. The Social Meaning of Money: Pin Money, Paychecks, Poor Relief, and Other Currencies. Princeton University Press.

Zelizer, Viviana A. 2011. Economic Lives. Princeton University Press. 